\title{
Research Progress of Reactor Thermal-Hydraulic Characteristics Under Ocean Conditions in China
}

Xin Jie*

Shandong Nuclear Power Co., Ltd. Shandong, China

Floating nuclear power plants are affected by sea wind and waves, which will produce various forms of movement, and cause changes in the thermal and hydraulic characteristics of the reactor core and threaten the safety of reactor operation. In response to the $R \& D$ and design requirements of floating nuclear power plants, the research progress on the thermal-hydraulic characteristics of reactors under ocean conditions in China are reviewed in this paper. The emphasis is put on flow heat transfer, bubble behavior, flow instability, and critical heat flux under ocean conditions. Research progresses as well as the issues that need to be focused on in the future research are discussed in detail.

OPEN ACCESS

Edited by:

Dalin Zhang,

Xi'an Jiaotong University, China

Reviewed by:

Yixiang Liao,

Helmholtz-Zentrum Dresden-

Rossendorf (HZ), Germany

Victor Petrov,

University of Michigan, United States

${ }^{*}$ Correspondence:

Xin Jie

xinjie@spic.com.cn

Specialty section:

This article was submitted to

Nuclear Energy,

a section of the journal

Frontiers in Energy Research

Received: 10 August 2020

Accepted: 05 October 2020

Published: 30 November 2020

Citation:

Jie X (2020) Research Progress of

Reactor Thermal-Hydraulic

Characteristics Under Ocean

Conditions in China.

Front. Energy Res. 8:593362.

doi: 10.3389/fenrg.2020.593362
Keywords: flow fluctuation, ocean conditions, thermal hydraulic, floating nuclear reactor, marine nuclear power

\section{INTRODUCTION}

Promoting the development and utilization of marine resources has become one of the important directions of development at this stage. The development of marine resources and the construction of coastal islands and reefs require reliable energy supply as a guarantee. Offshore floating nuclear power plants are marine operation equipment equipped with small reactors. They have the advantages of sustainable energy supply, clean and environmental protection, good mobility, and do not occupy land resources. They can be used in offshore power supply, cogeneration and seawater desalination. The best way to energy supply problems has broad market application prospects. Affected by sea environment such as sea surface wind and waves and its own maneuvering factors, offshore floating nuclear power plants will produce multi-degree-of-freedom hull motion during actual operation, triggering fluctuations in system thermal parameters such as coolant flow, and changing the thermal and hydraulic characteristics of the reactor. It poses a potential threat to the operational safety of the reactor. Since the 1960 s, the United States, Germany, Japan and other countries have successively carried out relevant studies on the impact of ocean conditions on reactors. With the rapid development of China's marine nuclear power, many domestic scientific research institutions such as Harbin Engineering University and China Nuclear Power Research and Design Institute have conducted a large number of theoretical analysis, numerical simulation and experimental research on the thermal and hydraulic characteristics of reactors under ocean conditions (Gao et al., 1997b; Ma et al., 2011; Tan et al., 2013; Lee et al., 2015; Li et al., 2017; Yan, 2017). Based on the published literature, this paper reviews the domestic and foreign research progress and important results of the thermal and hydraulic characteristics of reactors under 
TABLE 1 | Progress in R\&D of floating nuclear power plants

\begin{tabular}{|c|c|c|}
\hline Country & Representative model and technical features & R\&D stage \\
\hline Russia & $\begin{array}{l}\text { Lomonosov: Barge-style design, equipped with } 2 \mathrm{KLT}-40 \mathrm{~S} \\
\text { reactors, providing } 70 \mathrm{MW} \text { electric power and } 300 \mathrm{MW} \text { heat } \\
\text { energy }\end{array}$ & Sea test \\
\hline United States & $\begin{array}{l}\text { OFNP series: Cylindrical platform design, equipped with } \\
\text { Westinghouse small reactor, target electric power } \\
\text { 300-1,100 MW, using passive safety technology }\end{array}$ & Concept design \\
\hline France & $\begin{array}{l}\text { FLEXBLUE: sinking, column-shaped full-module floating design, } \\
\text { using French submarine reactor technology, single module } \\
\text { electric power } 160 \mathrm{MW}\end{array}$ & Concept design \\
\hline Korea & $\begin{array}{l}\text { GBS floating nuclear power plant: gravity-based structural design, } \\
\text { using Korean SMART reactor technology and passive safety } \\
\text { technology }\end{array}$ & Concept design \\
\hline China & $\begin{array}{l}\text { HHP25: Non-self-propelled ship-type platform + double-stack } \\
\text { arrangement; ACPR50S: Self-propelled ship-type platform + } \\
\text { compact small-scale reactor; ACP100S: Integrated small-scale } \\
\text { reactor design, adopting active + passive safety system }\end{array}$ & Demonstration power station construction \\
\hline
\end{tabular}

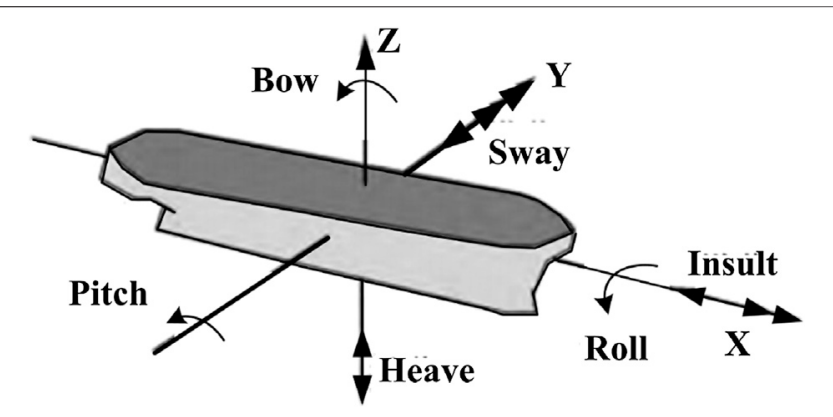

FIGURE 1 | Six degrees-of-freedom ship motions under ocean conditions.

ocean conditions, analyzes the deficiencies in the past research and puts forward relevant recommendations for future research.

\section{ANALYSIS OF THE POTENTIAL IMPACT OF OCEAN CONDITIONS}

Table 1 shows the current research and development progress of floating nuclear power plants in various countries in the world. It can be seen that Chinese floating nuclear power plants mostly adopt ship-type platform designs. It is generally believed that there will be a six-degree-of-freedom space movement as shown in Figure 1 when a ship-type platform is operating in real sea conditions. These forms of motion mainly affect the nuclear power system in two aspects: 1) The tilting and swaying motion of the hull will cause changes in the space position of the pipeline and equipment in the reactor system, resulting in a change in the effective height difference between the cold and heat sources, which in turn affects the system's performance, e.g., natural circulation capability. For reactors with multiple loops, the tilt of the hull will cause uneven distribution of natural circulation flow between loops and increase the heat transfer burden on the cold end on one side. In the inclined two-phase heating channel vaporization may occur. The local accumulation of vapor on the wall causes deterioration of heat transfer and induces a boiling crisis. 2) The undulating and swaying motion of the hull will introduce a periodically changing additional inertial force field, which is mainly caused by the additional acceleration such as tangential acceleration, centripetal acceleration and Coriolis acceleration caused by the motion conditions. The additional acceleration parallel to the flow direction will produce additional pressure drop for the fluid, causing periodic flow fluctuations or drift in the system, causing flow resistance, flow transition, boiling heat transfer, two-phase flow pattern, and flow instability as well as changes in thermal-hydraulic characteristics such as critical heat flux (CHF). In addition, for equipment with free liquid level such as voltage stabilizers and evaporators, sloshing, swaying and other forms of motion will also cause equipment level fluctuations, which may cause a series of problems such as exposed heating elements and distortion of liquid level measurement.

\section{RESEARCH ON FLOW AND HEAT TRANSFER CHARACTERISTICS UNDER OCEAN CONDITIONS}

Compared with other forms of hull motion, the influence of rocking motion is the most complicated, so it has received extensive attention in previous studies. The most direct impact of rocking motion on the reactor system is that it causes fluctuations in the flow of coolant. Gao Puzhen and other scholars established a mathematical model considering that the coolant flow in the loop is affected by ocean conditions, and analyzed the force of the coolant and the influence of various additional inertial accelerations on the fluctuation of the coolant flow. Tan et al. (2013) and Wang et al. (2014) have explored the causes of flow fluctuations under rocking conditions, and found that the flow fluctuation cycle under rocking conditions is consistent with the motion cycle, and the flow fluctuation behavior is mainly affected by the three factors of loop driving force, resistance and additional inertial force. The impact has nothing to do with the circulation mode of the loop, and the amplitude of flow fluctuations increases with the increase of the additional inertial force. Increasing 
the loop driving force or decreasing loop resistance helps to suppress the flow fluctuations caused by swing. Wang's research confirms that whether rocking motion can cause flow fluctuations depends on the relative magnitude of the additional inertial force and the driving force in the loop. When the driving force is greater than 10 times the additional inertial force, the impact of the rocking motion can be ignored.

Affected by flow fluctuations, the flow resistance characteristics in the loop will change under sway conditions. Cao et al. (2007) and Xing et al. (2013) studied experimentally the resistance characteristics of single-phase forced circulation flow in vertical circular pipe channels and rectangular channels under rocking motion. The research found that the single-phase frictional resistance coefficient under rocking conditions would be as periodic as the rocking motion. Factors such as fluctuation, Reynolds number, runner size, swing period and amplitude will also affect the instantaneous friction resistance, but the timeaveraged resistance coefficient is not significantly affected by the swing motion. Tan et al. found that the use of different calculation methods for time-averaged frictional resistance coefficients will result in large differences in the influencing law of the obtained time-averaged resistance coefficients in the laminar flow zone under ocean conditions. Among them, the time-averaged pressure drop and velocity, the method of drag coefficient accords with the experimental result better.

In, Yan et al. (2015) 's isocyclic experiment found that rocking motion has no significant effect on the single-phase and two-phase frictional resistance in the unheated rod bundle channel and the time-average value of the local resistance of the positioning grid. The gas flow, liquid flow, rocking parameters and channel size are important factors that affect the characteristics of two-phase instantaneous flow resistance under rocking conditions, and a dimensional analysis method is used to obtain the calculation method of two-phase flow resistance under rocking conditions. In Chen et al. (2015) found in the experiment of boiling twophase friction pressure drop characteristics in a narrow rectangular channel that the average value of the two-phase friction pressure drop in the heating channel and its fluctuation amplitude will increase with the swing amplitude, swing period and heat flux density. Compared with the two-phase pressure drop in the heating channel, the additional pressure drop caused by the rocking motion can be ignored.

Wang, (2013) conducted an experimental study on the heat transfer characteristics of forced circulation single-phase flow in a narrow rectangular channel under rocking conditions, and found that the time-averaged heat transfer characteristics of the pulsating flow under rocking motion are basically the same as the heat transfer characteristics of the steady flow in the static state. The heat transfer characteristics are greatly affected by the rocking motion, and the relationship between time-averaged and instantaneous heat transfer in single-phase forced circulation under rocking conditions is proposed. Chen et al. (2015, 2016) found that rocking motion will cause periodic fluctuations in the instantaneous heat transfer coefficient under saturated boiling conditions in a narrow rectangular channel, but the time average heat transfer coefficient is not affected by the rocking motion. Characteristics of two-phase flow pattern and its conversion law under the action of rocking motion have been discovered. However, the two-phase flow in related studies is mostly simulated by air and water, and the relevant conclusions are applied in boiling two-phase flow. The applicability of the extrapolation needs further verification. In terms of bubble behavior research, researchers have realized that flow fluctuations caused by additional external forces can cause local behavior changes such as the growth and separation of boiling bubbles, but the understanding of the microscopic mechanism of bubble action by ocean conditions is still not uniform. The introduction of refined full-field visualization measurement methods to obtain microscopic bubble behavior characteristics under ocean conditions, and then to build a physical mechanism model of the effects of ocean conditions is one of the directions for future research.

Murata et al. (1990, 2000) and Ishida and Yoritsune (2002) found in the study of the natural circulation of marine nuclear reactors that the rocking motion will increase the heat transfer efficiency of the core under natural circulation conditions. Tan et al. (2007a, 2009a, 2009b) gave the bottom term of the single-phase natural circulation flow heat transfer in a vertical tube under the rocking motion. In the characteristic experiment, it is found that compared with the static natural circulation, the average flow rate of the natural circulation of the rocking condition is reduced, but the heat transfer capacity is enhanced; the fluctuation amplitude of the fluid temperature is greater than the fluctuation amplitude of the wall temperature, and it is affected by the single-phase due to the influence of heat storage on the zone wall, where a large difference between the fluid temperature fluctuation curve and the wall temperature fluctuation curve exists. Based on the experimental results, an empirical formula for calculating the natural circulation heat transfer coefficient under rocking conditions is proposed. Huang et al., (2010) believe that the increased local disturbance of the flow near the wall of the heating tube caused by the swing is the main reason for the enhancement of the natural circulation heat transfer.

In addition to the rocking motion, the researchers also carried out related research items on the flow and heat transfer characteristics of the reactor under tilting and undulating motion conditions. Studies have found that tilting will cause the natural circulation capability of the reactor system to decrease (Gao et al., 1997a; Gao et al., 1999; Kim et al., 2001; Jiang et al., 2009; Yang et al., 2013; Gong et al., 2014). The greater the angle of inclination, the more the thermal drive head between the core and the steam generator decreases, and the more the natural circulation capacity decreases. For an integrated reactor, the tilt will cause the height difference between the left and right loops of the cold and heat sources. Changes have occurred, resulting in significant differences in the primary flow rate of the heat exchangers on both sides, resulting in different heat exchange powers of the heat exchangers on both sides, and large differences in the steam output and quality of the secondary side, which affect the control of the secondary loop of the reactor. Similar to the influence of rocking motion, the alternating force field composed of additional force and gravity introduced by undulating motion will cause flow fluctuations in natural circulation. The greater the undulating intensity and the longer the period, the greater the amplitude of flow fluctuations, and the largeperiod undulating motion. The flow fluctuations show nonlinear 
TABLE 2 | Experimental investigations on thermal hydraulics characteristics in-pipe under single dimensional swing in China

\begin{tabular}{|c|c|c|c|c|c|}
\hline \multirow[t]{2}{*}{ Cyclic way } & \multirow[t]{2}{*}{ Experimental section } & \multicolumn{2}{|c|}{ Swing parameter } & \multirow[t]{2}{*}{ Thermal hydraulic parameters } & \multirow[t]{2}{*}{ Research content } \\
\hline & & Angle & Period/s & & \\
\hline Natural circulation (Tan et al., 2013) & Vertical tube with inner diameter $30 \mathrm{~mm}$ & $0-45^{\circ}$ & $7-14$ & $\begin{array}{l}\text { Atmospheric pressure, inlet water temperature } \\
8-35^{\circ} \mathrm{C}\end{array}$ & Single-phase water heat transfer \\
\hline Natural circulation (Cao et al., 2007) & Vertical tube with inner diameter $14 \mathrm{~mm}$ & $10-20^{\circ}$ & $5-15$ & $\begin{array}{l}\text { Inlet subcooling degree } 10-60^{\circ} \mathrm{C} \text {, pressure } \\
0.1-0.4 \mathrm{MPa}\end{array}$ & $\begin{array}{l}\text { Single-phase water flow and heat transfer, } \\
\text { instability of two-phase flow }\end{array}$ \\
\hline Natural circulation (Xing et al., 2013) & $\begin{array}{l}\text { Vertical annular channel with an annular gap } \\
\text { thickness of } 7.5 \mathrm{~mm}\end{array}$ & $5-15^{\circ}$ & $5-10$ & $\begin{array}{l}\text { Pressure } 0.12 \mathrm{MPa} \text {; flow velocity } 0.02-0.168 \mathrm{~m} / \mathrm{s} \text {, } \\
\text { inlet subcooling degree } 26-42^{\circ} \mathrm{C}\end{array}$ & Critical heat flux \\
\hline Forced circulation (Yan, 2015) & $\begin{array}{l}\text { Vertical round pipe with inner diameter } 15,25 \text {, } \\
\qquad 34.5 \mathrm{~mm}\end{array}$ & $10-20^{\circ}$ & $5-15$ & $\begin{array}{l}\text { Normal temperature and pressure, water flow } \\
\text { rate } 0-10 \mathrm{~m}^{3} / \mathrm{h} \text {; air flow rate } 0.16-44 \mathrm{~m}^{3} / \mathrm{h}\end{array}$ & $\begin{array}{l}\text { Single-phase water, air-water two-phase bubbly } \\
\text { flow, annular flow friction pressure drop } \\
\text { characteristics, gas-liquid two-phase flow } \\
\text { pattern and cross-section gas content }\end{array}$ \\
\hline Forced circulation (Chen et al., 2015) & $34.5 \mathrm{~mm}$ inner diameter horizontal round pipe & $10-20^{\circ}$ & $10-20$ & $\begin{array}{l}\text { Normal temperature and pressure, flow velocity } \\
0.15-2.4 \mathrm{~m} / \mathrm{s}\end{array}$ & Single-phase water friction pressure drop \\
\hline Forced circulation (Wang, 2013) & Horizontal round tube with inner diameter $24 \mathrm{~mm}$ & $10^{\circ}$ & 15 & $\begin{array}{l}\text { Pressure } 0.1 \mathrm{MPa} \text {, inlet water temperature } \\
10-28^{\circ} \mathrm{C}, \text { liquid phase conversion flow rate } \\
0.03-3.3 \mathrm{~m} / \mathrm{s} \text {, gas phase conversion flow rate } \\
0.06-30 \mathrm{~m} / \mathrm{s}\end{array}$ & Air-water two-phase flow pattern \\
\hline $\begin{array}{l}\text { Forced circulation (Chen et al., 2015; Chen } \\
\text { et al., 2016) }\end{array}$ & Horizontal round tube with inner diameter $25 \mathrm{~mm}$ & $10^{\circ}$ & 15 & $\begin{array}{l}\text { Normal temperature and pressure, air flow rate is } \\
0.1-40 \mathrm{~m}^{3} / \mathrm{h} \text {, water flow rate is } 0-4.0 \mathrm{~m}^{3} / \mathrm{h}\end{array}$ & Air-water two-phase flow pattern \\
\hline $\begin{array}{l}\text { Forced circulation (Murata et al., 1990; Murata } \\
\text { et al., 2000) }\end{array}$ & $\begin{array}{l}\text { Horizontal round tube with inner diameter } \\
34.5 \mathrm{~mm}\end{array}$ & $20^{\circ}$ & 14.6 & $\begin{array}{l}\text { Normal temperature and pressure, air flow rate is } \\
0.2-40 \mathrm{~m}^{3} / \mathrm{h} \text {, water flow rate is } 0-4.0 \mathrm{~m}^{3} / \mathrm{h}\end{array}$ & Air-water two-phase flow pattern \\
\hline Forced circulation (Ishida and Yoritsune, 2002) & $\begin{array}{l}\text { Vertical round tube with inner diameter } 25 \text { and } \\
34.5 \mathrm{~mm}\end{array}$ & $20^{\circ}$ & 10 & $\begin{array}{l}\text { Normal temperature and pressure, water flow } \\
0.2-1.5 \mathrm{~m}^{3} / \mathrm{h} \text {, air flow } 0.28-2.0 \mathrm{~m}^{3} / \mathrm{h}\end{array}$ & Air-water two-phase flow pattern, cavity share \\
\hline $\begin{array}{l}\text { Forced circulation (Tan et al., 2007a; Tan et al., } \\
\text { 2009a; Tan et al., 2009b) }\end{array}$ & Vertical tube with inner diameter $8 \mathrm{~mm}$ & $10-20^{\circ}$ & $5-10$ & $\begin{array}{l}\text { Pressure } 0.5-3.5 \mathrm{MPa} \text {, inlet subcooling degree } \\
10-50^{\circ} \mathrm{C} \text {, flow velocity } 0.5-7.2 \mathrm{~m} / \mathrm{s}\end{array}$ & Critical heat flux \\
\hline Forced circulation (Huang et al., 2010) & $\begin{array}{l}\text { Vertical annular channel with an annular gap } \\
\text { thickness of } 7.5 \mathrm{~mm}\end{array}$ & $5-15^{\circ}$ & $5-10$ & $\begin{array}{l}\text { Pressure } 0.12 \mathrm{MPa} \text {, flow rate } 0.97-2.06 \mathrm{~m} / \mathrm{s} \text {, } \\
\text { inlet subcooling degree } 9-43^{\circ} \mathrm{C}\end{array}$ & Critical heat flux \\
\hline
\end{tabular}


changes, which may cause core exit boiling phenomenon and have a greater impact on the core. The researchers clarified the influence mechanism and boundary of flow fluctuations under ocean conditions, and formed systematic conclusions on the heat transfer characteristics of single-phase flow under the action of rocking motion. However, the understanding of the two-phase flow resistance and boiling heat transfer characteristics under ocean conditions is insufficient, and the related researches are mostly focused on forced circulation, and relatively few researches have been carried out under natural circulation conditions. In the future, it is necessary to conduct further research on the flow and heat transfer characteristics of two-phase natural circulation under ocean conditions. More attention can be paid to the rod bundle fuel element channel form that widely used in floating reactors.

Among the various motions caused by ocean conditions, rocking motion is a typical motion mode with higher frequency. The additional acceleration generated usually puts the ship reactor in a transient non-conservative force field operating environment, which affects the coolant system. The influence is far more complicated than the additional conservative force field formed by the gravity field and the undulating motion. Therefore, the research on the thermal-hydraulic characteristics of ship reactors under rocking conditions has become the current research focus. The research team represented by scientific research institutions such as Harbin Engineering University has built a simple singledegree-of-freedom swing experimental loop to simulate the swing motion under ocean conditions, and carried out a large number of single-phase and two-phase thermal hydraulics in conventional circular channels under swing or ocean conditions (as shown in Table 2).

\section{Research on Local Bubble Behavior and Flow Pattern Conversion Characteristics}

The bubble in the boiling channel under ocean conditions is in a periodically changing inertial force field, and the behavior of the bubble is significantly different from that under static conditions. In the process of studying the local bubble behavior in the boiling channel, most researchers attribute the impact of ocean conditions to changes in system flow.

In Hong et al. (2012) conducted a visual experimental study on the detachment diameter of the supercooled boiling bubble under fluctuating conditions. It was found that the detachment diameter of the bubble was affected by the additional acceleration and flow fluctuations caused by the fluctuating motion. Based on this, a correlation was derived for the determination of the bubble detachment diameter under bubble under the fluctuating conditions. Qin and Gao (2008) found that the additional acceleration generated by the swing has negligible influence on the force of the bubble itself, while flow fluctuations will cause the position of the bubble's departurto change. Among other experimental studies, Xie et al. (2014a, 2014b) found that local flow field fluctuations caused by rocking motion would make the growth of bubbles become unstable, and they established a prediction model of bubble separation in narrow-slit channels under rocking conditions. Li (2015) believed that the influence of ocean conditions on the behavior of local vapor bubbles in the supercooled flow boiling channel mainly has three aspects: the direct influence of the additional acceleration field of the ocean conditions, the change of thermal boundary conditions and the influence of unsteady factors. The change of boundary conditions was found to be the main reason that ocean conditions affect local bubble behavior, and a prediction model for bubble behavior and subcooled boiling heat transfer under ocean conditions was proposed.

In the study of the transition characteristics of two-phase flow patterns under ocean conditions, Yan et al. (2008) found through experiments that swaying motion can transform bubbly flow into slug flow in advance, and widen the area of mixed flow. In the slug flow area, the cavitation fraction of two-phase flow under swaying motion is less than its static value. Wang et al. (2011) found that due to the increase in surface tension in the narrow rectangular channel and the increase in the frictional resistance pressure drop, the effect of sway on the two-phase flow pattern is not obvious. Zhang (2009) conducted experimental research on the flow pattern conversion characteristics in horizontal and vertical circular pipe channels under rocking motion, and obtained the classification and conversion law of the two-phase flow pattern in the pipe under the action of additional periodic force field. By modifying the Chisholm model parameters, the calculation formula of friction pressure drop of annular flow under suitable rocking conditions is obtained. Jia et al. (2006) found that under the same liquid phase converted flow rate, an increase in pipe diameter, a shortened swing period, or a reduced swing amplitude will cause the formation of annular flow at a higher vapor phase converted flow rate.

\section{Research on Flow Instability and CHF in Ocean Conditions}

There are many types of two-phase flow instability and complex influencing factors, coupled with periodic flow fluctuations caused by ocean conditions, will cause complex nonlinear phenomena in the reactor system. Ishida et al. (1997) found that under fluctuating conditions, when the system self-sustained pulsation and the pulsation caused by the change of the gravitational field will resonate superimposed, the fluctuation of the system parameters will increase. Tan and Pang (2005) and Tan et al. (2007b, 2008, 2009c) experimentally studied the flow instability of two-phase natural circulation in a circular pipe channel under rocking conditions, and the results showed that rocking motion will cause the start point of natural circulation flow instability to advance. Under rocking conditions, flow instability (trough-shaped pulsation) will first occur at the trough point of flow fluctuations. The valley-shaped pulsation and density wave pulsation caused by rocking motion will form compound pulsation after superimposing, which will aggravate the system instability. Guo et al. (2008) conducted a numerical simulation study on the influence of ocean conditions on the instability of the natural circulation flow in parallel channels, and the results showed that there are two instabilities in the parallel channel under sway conditions, which are located in the high gas content area and the low gas content area, respectively. The nonlinear characteristics of the natural circulation system under 
rocking conditions are obvious. With the increase of heating power, period-doubling bifurcation will appear, and chaos may appear as well.

Tang et al. (2014) found in the experiment of instability of forced circulatory flow in parallel rectangular channels under ocean conditions that tilt, undulation and rocking motion have little effect on the thermal power and stability boundary, and the two-phase flow is unstable. The occurrence of instability is mainly determined by the thermal conditions of the system rather than the influence of ocean conditions. Yu et al. (2016) carried out an experimental study on the instability of forced circulation in a narrow rectangular channel under rocking conditions, and obtained the characteristics and evolution of the trough-shaped pulsation and compound pulsation under rocking conditions, and confirmed the observation of the compound pulsation in the experiment. The generation is the result of the superposition of trough-type pulsation and pressure drop-type pulsation.

Due to the strong nonlinear characteristics of flow instability under ocean conditions, researchers tried to apply nonlinear analysis methods and chaos theory to research in this field. Guo et al. (2010) found that the fast Fourier transform (FFT) method can effectively identify the occurrence of flow instability under ocean conditions and evaluate the impact of ocean conditions. Zhang et al. (Zhang et al., 2012; Zhang et al., 2014) used the method of chaotic time series analysis to study the chaotic characteristics and mechanism of the system flow pulsation in the swing condition, and analyzed the synchronization law of the regular compound pulsation that found in the experiment. They obtained the non-linear evolution mechanism of instability for natural circulation flow under motion conditions.

In the study of the critical phenomenon of boiling and the characteristics of critical heat flux (CHF) in a two-phase boiling system under ocean conditions, experiments by Isshiki (1966) proved that tilting and undulating movements can cause a decrease in CHF value. The color item of Otsuji and Kurosawa (1982), Otsuji and Kurosawa (1983), Otsuji and Kurosawa (1984) showed that the advancement of CHF caused by undulating motion has a linear relationship with the amplitude of undulating motion. Under low inlet subcooling conditions, the early occurrence of $\mathrm{CHF}$ can be completely attributed to flow fluctuations. Under the subcooled boiling conditions corresponding to high inlet subcooling, the outlet gas content fluctuates significantly and is caused by undulating motion. The CHF reduction is even more significant. Pang et al. (1997) and Gao et al. (1997c) conducted experimental studies on the characteristics of $\mathrm{CHF}$ in forced circulation and natural circulation channels under rocking motion. The results showed that rocking motion caused a decrease in CHF. Gao et al. (1997c) believed that the flow fluctuation caused by rocking motion was the main reason for $\mathrm{CHF}$ reduction. There are big differences in the laws of influence of ocean conditions on the flow instability boundary of natural circulation and forced circulation obtained by different researchers. There is not much research on CHF under ocean conditions, and the current understanding of the mechanism of CHF under ocean conditions is insufficient. In the future, it is necessary to continue carrying out related research on flow instability and $\mathrm{CHF}$ characteristics under ocean conditions, expand the range of thermal hydraulics and ocean condition parameters studied, and improve the understanding of the laws and mechanisms of ocean conditions.

Hwang et al. (2012) chose R-134a as the experimental working fluid and studied the influence of rocking motion on the critical heat flux density in the upward-flowing heating tube under forced circulation conditions, and proposed the mechanism of rocking conditions on $\mathrm{CHF}$.

1) In the DNB region (i.e. when the flow rate is higher than a certain value under medium or high pressure), due to the mixing of the bubble boundary layer and the enhancement of the bubble separation rate, the combined action of the tangential force and the high-quality flow velocity promotes the increase of CHF under rocking conditions.

2) In the Dryout area (that is, when the medium pressure is lower than a certain flow value), the rocking motion will reduce the thickness of the liquid film of the annular flow, which will lead to the occurrence of $\mathrm{CHF}$ under rocking conditions.

Liu et al. (2012) developed a subcooled flow boiling CHF prediction model based on the micro-liquid layer evaporation model, and studied the applicability of the model under motion conditions. The results revealed that the $\mathrm{CHF}$ under motion conditions increases with axial acceleration and bubble diameter. When the thermal and hydraulic conditions become worse (such as low inlet subcooling, low mass flow or high gas content), the impact of these two effects on CHF becomes more prominent. Liu et al. (2018) carried out a numerical simulation study on the flow instability and CHF characteristics of parallel heating channels under ocean conditions, and found that the uneven flow distribution of parallel channels caused by heeling and the flow pulsation caused by sway would cause the early occurrence of CHF.

\section{Development of Numerical Analysis Tools and Analysis of System Characteristics}

The thermal-hydraulic system analysis program is an important tool for reactor design and safety analysis. The existing reactor system analysis programs are mostly developed for land-based reactors, and cannot perform thermal-hydraulic calculations of reactors under ocean conditions. By replacing the original steady gravity field with the acceleration field under ocean conditions, Ishida and Tomiai (1992) corrected the mass force source term of the control equation in the RETRAN-02 program, and developed a safety analysis suitable for thermal hydraulic systems under ocean conditions. This method of introducing the influence of ocean conditions by modifying the mass force source item is followed by subsequent program developers (Wang and Tian, 2019a; Wang and Tian, 2019b; Wang and Tian, 2019c; Wang et al., 2019).

The characteristics of "island operation" of marine nuclear power plants lead to the lack of sufficient external energy support 
in accident conditions, and passive safety technologies are widely adopted in the design of existing floating reactors (Wang et al., 2020a; Wang et al., 2020b; Wang et al., 2020c; Wang et al., 2020d). Since passive safety systems mostly use natural circulation and flow diffusion, the impact of ocean conditions on passive safety systems cannot be ignored. Based on the developed ocean condition system analysis program, domestic and foreign researchers have carried out calculation and analysis on the operating characteristics of marine passive safety systems under ocean conditions. Zhang et al. (2017) used the RELAP5$3 \mathrm{D}$ program to evaluate the safety performance of the OFNP-300 floating nuclear power plant under sea conditions under power outages and breach accidents. Inertial acceleration models of a coolant under ocean conditions were established based on the mathematical description of typical ship movement. A thermal hydraulic system analysis code suitable for marine nuclear plants was developed by adding an ocean condition calculation module to a commercial system analysis program. Experimental validation and comparison with different codes were performed to evaluate the validity of ocean condition modeling and program modification. Result shows that the developed code can effectively simulate the flow fluctuation experiment under rolling condition, and the calculation results under different motion conditions are in good agreement with those of RETRAN-02/GRAV and other codes of the same type, thereby verifying the reliability of the code calculation results under motion conditions. Yang et al. (2015) studied the impact of marine conditions on the accident process after the power failure of the entire floating reactor plant, and evaluated the applicability of the existing primary and secondary passive residual heat removal system design under marine conditions. Mathematical models of ocean conditions have been studied. By modifying the control equations, an ocean condition available system analysis code named RELAP5/MC is developed from RELAP5, which is an advanced and independent node programming code. Calculation of the natural circulation characteristics of a simple two loop system under ocean conditions has been carried out with RELAP5/MC. The analysis shows that all the results can be reasonably explained and the code development is successful at this stage.

\section{CONCLUSION AND PERSPECTIVE}

In summary, domestic and foreign researchers have carried out a lot of research work on the related issues of reactor thermalhydraulic characteristics under ocean conditions. The related research is mainly based on mechanism experiments, and relatively complete research methods and technologies have been formed. Means have enriched the understanding of the impact of ocean conditions. A summary of the current research status and future research prospects are given as follows.

1) In terms of the study of flow and heat transfer characteristics, the researchers clarified the influence mechanism and boundary of flow fluctuations under ocean conditions, and formed systematic conclusions on the heat transfer characteristics of single-phase flow under the action of rocking motion. However, the understanding of the two-phase flow resistance and boiling heat transfer characteristics under ocean conditions is insufficient, and the related researches are mostly focused on forced circulation, and relatively few researches have been carried out under natural circulation conditions. In the future, it is necessary to conduct further research on the flow and heat transfer characteristics of two-phase natural circulation under ocean conditions. Furthermore, the research objects can be extended to rod bundle fuel element channels, which are widely used in floating reactors.

2) In the study of two-phase flow pattern, the characteristics of two-phase flow pattern and its conversion law under the action of rocking motion have been discovered. However, the two-phase flow in related studies is mostly simulated by air and water, and the relevant conclusions are applied in boiling two-phase flow. The applicability of this extrapolation needs further verification. In terms of bubble behavior research, researchers have realized that flow fluctuations caused by additional external forces can cause local behavior changes such as the growth and separation of boiling bubbles, but the understanding of the microscopic mechanism of bubble action by ocean conditions is still not uniform. The introduction of refined full-field visualization measurement methods to obtain microscopic bubble behavior characteristics under ocean conditions, and then to build a physical mechanism model of the effects of ocean conditions is one of the directions for future research.

3) The phenomenon of flow instability under ocean conditions shows strong nonlinear characteristics, and there are big differences in the laws of influence of ocean conditions on the flow instability boundary of natural circulation and forced circulation obtained by different researchers. There is not much research on CHF under ocean conditions, and the current understanding of the mechanism of CHF under ocean conditions is insufficient. In the future, it is necessary to continue to carry out related research on flow instability and CHF characteristics under ocean conditions, expand the range of thermal hydraulics and ocean condition parameters studied, and improve the understanding of the laws and mechanisms of ocean conditions.

4) The thermal-hydraulic experiments under ocean conditions that have been carried out are mostly mechanistic studies. The research objects and experimental parameters are quite different from the real conditions of marine reactors, and the obtained empirical relationship model cannot meet the needs of marine reactor engineering design. Due to this limitation, the existing thermal-hydraulic system analysis programs of ocean conditions mostly use the thermal-hydraulic model under static conditions, and most of them lack systematic experimental verification to evaluate the errors caused by this. Therefore, the development of general thermal-hydraulic models for marine conditions and the verification and evaluation of special procedures for marine reactors are one of the key issues that need attention in this field in the future.

5) Compared with local thermal-hydraulic phenomena, there are limited researches on the overall thermal-hydraulic behavior of marine reactors and passive safety systems under ocean conditions. For passive residual heat removal systems and 
other systems coupled with multiple natural loops, the dynamic feedback response characteristics between the loops are affected by ocean conditions and the mechanism is still unclear. Therefore, in the future, key research can be carried out on the applicability of key systems of floating nuclear power plants, such as the passive waste heat removal system for ships, under ocean conditions.

6) From the perspective of the engineering design of floating nuclear power plants, for equipment with free liquid level such as voltage stabilizers and suppression pools in existing designs, the fluctuation of free liquid level caused by ocean conditions is important for the measurement of key parameters such as liquid

\section{REFERENCES}

Cao, X. X., Yan, C. Q., Sun, L. C., and Sun, Z. (2007). Pressure drop characteristics of single-phase flow in vertical rolling pipes. Nucl. Power Eng. 28 (3), 51-55. doi:10.1016/S1003-6326(07)60294-5

Chen, C., Gao, P.-z., Tan, S.-c., Huang, D., and Yu, Z.-t. (2015). Effect of rolling motion on two-phase frictional pressure drop of boiling flows in a rectangular narrow channel. Ann. Nucl. Energy. 83, 125-136. doi:10.1016/j.anucene.2015. 03.049

Chen, C., Gao, P.-Z., Tan, S.-c., and Yu, Z.-t. (2016). Boiling heat transfer characteristics of pulsating flow in rectangular channel under rolling motion. Exp. Therm. Fluid Sci. 70, 246-254. doi:10.1016/j.expthermflusci.2015.09.013

Chen, C., Gao, P. Z., Tan, S. C., and Dong, H. (2015). Effects of rolling motion on thermal-hydraulic characteristics of boiling flow in rectangular narrow channel. Ann. Nucl. Energy. 76, 504-513. doi:10.1016/j.anucene.2014.10.024

Gao, P. Z., Pang, F. G., and Liu, S. Y.. (1997a). Effects of listing upon forced circulation and natural circulation. Chinese J. Nucl. Sci. Eng. 17 (2), 179-183. [in Chinese]

Gao, P. Z., Pang, F. G., and Wang, Z. X. (1997b). Mathematical model of primary coolant in nuclear power plant influenced by ocean conditions. J. Harbin Eng. Univ. 18 (1), 24-27. [in Chinese]

Gao, P. Z., Wang, Z. X., and Liu, S. L. (1999). Effects of heaving upon forced circulation and natural circulation. Chinese J. Nucl. Sci. Eng. 19 (2), 116-120

Gao, P. Z., Wang, Z. X., and Pang, F. G. (1997c). Experiments on critical heat flux of water under natural circulation with rolling movement. J. Harbin Eng. Univ. 18 (6), 38-42. [in Chinese]

Gong, H. J., Yang, X. T., and Huang, Y. P. (2014). Experimental and numerical study on natural circulation of integrated reactor under inclination condition. Nucl. Power Eng. 35 (5), 89-93. [in Chinese]

Guo, Y., Cheng, G., and Zeng, H. Y. (2010). The application of fast fourier transform (FFT) method in the twin-channel system instability under ocean conditions. Ann. Nucl. Energy. 37 (8), 1048-1055. doi:10.1016/j. anucene.2010.05.021

Guo, Y., Qiu, S. Z., Su, G. H., and Jia, D. N. (2008). The influence of ocean conditions on two-phase flow instability in a parallel multi-channel system. Ann. Nucl. Energy. 35 (9), 1598-1605. doi:10.1016/j.anucene. 2008.03.003.

Hong, G., Yan, X., Yang, Y.-h., Xie, T.-z., and Xu, J.-j. (2012). Bubble departure size in forced convective subcooled boiling flow under static and heaving conditions. Nucl. Eng. Des. 247, 202-211. doi:10.1016/j.nucengdes.2012.03.008

Huang, Z., Gao, P. Z., and Tan, S. C. (2010). Mechanism analysis of effect of rolling motion on heat transfer. Nucl. Power Eng. 31 (3), 50-54. [in Chinese]

Hwang, J.-S., Lee, Y.-G., and Park, G.-C. (2012). Characteristics of critical heat flux under rolling condition for flow boiling in vertical tube. Nucl. Eng. Des. 252, 153-162. doi:10.1016/j.nucengdes.2012.06.032

Ishida, I., and Tomiai, I., Development of analysis code for thermal hydro-dynamics of marine reactor under multi-dimensional ship motions, retran-02/grav. Tokyo, Japan, Japan Atomic Energy Research Inst., (1992). [in Japanese]

Ishida, T., Yao, T., and Teshima, N. (1997). Experiments of two-phase flow dynamics of marine reactor behavior under heaving motion. J. Nucl. Sci. Technol. 34 (8), 771-782. doi:10.1080/18811248.1997.9733741 level. The impact of equipment functions and related system control needs to be evaluated by related research.

\section{AUTHOR CONTRIBUTIONS}

XJ: Writing, idea and investigation.

\section{ACKNOWLEDGMENTS}

Many thanks to Shandong Nuclear Power Co., Ltd. for the help.

Ishida, T., and Yoritsune, T. (2002). Effects of ship motions on natural circulation of deep sea research reactor DRX. Nucl. Eng. Des. 215 (1-2), 51-67. doi:10.1016/ s0029-5493(02)00041-9

Isshiki, N. (1966). Effects of heaving and listing upon thermo-hydraulic performance and critical heat flux of water-cooled marine reactors. Nucl. Eng. Des. 4 (2), 138-162. doi:10.1016/0029-5493(66)90088-4

Jia, H., Cao, X. X., and Yan, C. Q. (2006). Experimental study on two - phase flow pattern transition in rolling tubes. Chinese J. Nucl. Sci. Eng. 26(3), 209-214, 198. [in Chinese]

Jiang, S. Y., Yang, X. T., and Gong, H. J. (2009). Mechanism of natural circulation taking account into heaving movement. Atomic Energy Sci. Technol. 43 (S1), 92-96. [in Chinese]

Kim, J.-H., Kim, T.-W., Lee, S.-M., and Park, G.-C. (2001). Study on the natural circulation characteristics of the integral type reactor for vertvaical and inclined conditions. Nucl. Eng. Des. 207 (1), 21-31. doi:10.1016/s0029-5493(00)00417-9

Lee, K.-H., Kim, M.-G., Lee, J., and Lee, P.-S. (2015). Recent advances in ocean nuclear power plants. Energies 8 (10), 11470-11492. doi:10.3390/en81011470

Li, J. J., and Liu, F., and Zhao, F. (2017). Development status of overseas offshore floating nuclear plant industry J. Ship Eng. 39 (4): 7-11. [in Chinese]

Li, S. D. Study of local bubble behavior and boiling heat transfer characteristics under ocean condition (In Chinese). Harbin: Harbin Engineering Univerisity, (2015).

Liu, D., Tian, W., Xi, M., Chen, R., Qiu, S., and Su, G. H. (2018). Study on safety boundary of flow instability and CHF for parallel channels in motion. Nucl Eng Des. 335, 219-230. doi:10.1016/j.nucengdes.2018.05.024

Liu, W. X., Tian, W. X., Wu, Y. W., Su, G. H., Qiu, S. Z., Yan, X., et al. (2012). An improved mechanistic critical heat flux model and its application to motion conditions. Prog. Nucl. Energy 61, 88-101. doi:10.1016/j.pnucene.2012.07.002

Ma, J., Li, L. J., and Huang, Y. P. (2011). Progress in investigations on thermohydraulic characteristics of ship nuclear reactors under ocean conditions. Nucl. Power Eng. 32 (2), 91-96. [in Chinese]

Murata, H., Iyori, I., and Kobayashi, M. (1990). Natural circulation characteristics of a marine reactor in rolling motion. Nucl. Eng. Des. 118 (2), 141-154. doi:10. 1016/0029-5493(90)90053-Z

Murata, H., Sawada, K.-i., and Kobayashi, M. (2000). Experimental investigation of natural convection in a core of a marine reactor in rolling motion. J. Nucl. Sci. Technol. 37 (6), 509-517. doi:10.1080/18811248.2000.9714924

Otsuji, T., and Kurosawa, A. (1982). Critical heat flux of forced convection boiling in an oscillating acceleration field - I. General trends. Nucl. Eng. Des. 71 (1), 15-26. doi:10.1016/0029-5493(82)90165-0

Otsuji, T., and Kurosawa, A. (1983). Critical heat flux of forced convection boiling in an oscillating acceleration field-II. Contribution of flow oscillation. Nucl. Eng. Des. 76 (1), 13-21. doi:10.1016/0029-5493(83)90043-2

Otsuji, T., and Kurosawa, A. (1984). Critical heat flux of forced convection boiling in an oscillating acceleration field - III. Reduction mechanism of CHF in subcooled flow boiling. Nucl Eng Des. 79 (1), 19-30. doi:10.1016/0029-5493(84) 90185-7

Pang, F. G., Gao, P. Z., and Wang, Z. X. (1997). Experimental investigation of effect of rolling upon critical heat flux (CHF) for water at atmospheric pressure. Chinese J. Nucl. Sci. Eng. 17 (4), 367-371. [in Chinese]

Qin, S. J., and Gao, P. Z. (2008). Effect of rolling motion on forces acting on bubbles in sub-cooled boilina flow. Nucl. Power Eng. 29 (2), 20-23 
Tan, S. C., Gao, P. Z., and Su, G. H. (2007a). Experimental and theoretical study on natural circulation flow under rolling motion condition. J. Harbin Eng. Univ. 28 (11), 1213-1217. [in Chinese]

Tan, S. C., Gao, P. Z., and Su, G. H. (2008). Experimental research on natural circulation complex oscillations under rolling motion conditions. Atomic Energy Sci. Technol. 42 (11), 1007-1011. [in Chinese]

Tan, S. C., Gao, W. J., and Gao, P. Z. (2007b). Effect of rolling motion on flow instability of natural circulation. Nucl. Power Eng. 28 (5), 42-45. [in Chinese]

Tan, S. C., and Pang, F. G. (2005). Overlapped flow of flow oscillation caused by rolling motion and density wave oscillation of natural circulation. Nucl. Power Eng. 26 (2), 140-143. [in Chinese]

Tan, S.-c., Su, G. H., and Gao, P.-z. (2009a). Experimental and theoretical study on single-phase natural circulation flow and heat transfer under rolling motion condition. Appl. Therm. Eng. 29 (14/15), 3160-3168. doi:10.1016/j. applthermaleng.2009.04.019

Tan, S. C., Su, G. H., and Gao, P. Z. (2009b). Heat transfer model of single-phase natural circulation flow under a rolling motion condition. Nucl. Eng. Des. 239(10), 2212-2216. doi:10.1016/j.nucengdes.2009.05.002

Tan, S. C., Su, G. H., and Gao, P. Z. (2009c). Experimental study on two-phase flow instability of natural circulation under rolling motion condition. Ann. Nucl. Energy. 36 (1), 103-113. doi:10.1016/j.anucene.2008.09.014

Tan, S., Wang, Z., Wang, C., and Lan, S. (2013). Flow fluctuations and flow friction characteristics of vertical narrow rectangular channel under rolling motion conditions. Exp. Therm Fluid Sci. 50, 69-78. doi:10.1016/j.expthermflusci.2013. 05.006

Tang, Y., Chen, B.-d., Xiong, W.-y., and Liu, X.-z. (2014). Comparison of flow instabilities under static condition and marine motion conditions based on experiments. Ann. Nucl. Energy. 70, 11-20. doi:10.1016/j.anucene.2014.02. 010

Wang, B., Chen, B., and Tian, R. (2019). Review of research progress on flow and rupture characteristics of liquid film on corrugated plate wall. Ann. Nucl. Energy. 132, 741-751. doi:10.1016/j.anucene.2019.06.060

Wang, B., Chen, B., Ke, B., Wang, G., Li, R., Wen, J., et al. (2020a). Analysis of the flow characteristics of the liquid film on the wall surface of the corrugated plate dryer based on PSD method: a short communication. Front. Energy Res. 8, 215. doi:10.3389/fenrg.2020.00215

Wang, B., Chen, B., Ke, B., Wang, G., Li, R., Wen, J., et al. (2020b). Study on the breakdown mechanism of water film on corrugated plate wall under the horizontal shear of airflow: a short communication. Front. Energy Res. 8, 197. doi:10.3389/fenrg.2020.00197

Wang, B., Chen, B., Wen, J., and Tian, R. (2020c). A mini review of research progress of nuclear physics and thermal hydraulic characteristics of leadbismuth research reactor in China Front. Energy Res. 8, 573199. doi:10. 3389/fenrg.2020.573199

Wang, B., Chen, B., Wen, J., Lu, C., and Tian, R. (2020d). Review and prospect of the measurement technology of the thickness of the liquid film on the wall of the corrugated plate dryer. Front. Energy Res. 8, 214. doi:10.3389/fenrg.2020.00214

Wang, B., and Tian, R. (2019a). Investigation on flow and breakdown characteristics of water film on vertical corrugated plate wall. Ann. Nucl. Energy. 127, 120-129. doi:10.1016/j.anucene.2018.12.001

Wang, B., and Tian, R. (2019b). Judgement of critical state of water film rupture on corrugated plate wall based on SIFT feature selection algorithm and SVM classification method. Nucl. Eng. Des. 347, 132-139. doi:10.1016/j.nucengdes. 2019.03.025

Wang, B., and Tian, R. (2019c). Study on characteristics of water film breakdown on the corrugated plate wall under the horizontal shear of airflow. Nucl. Eng. Des. 343, 76-84. doi:10.1016/j.nucengdes.2018.12.018
Wang, C., Study of flow and heat transfer in rectangular channel in periodic force field (In Chinese). Harbin: Harbin Engineering Univerisity, (2013).

Wang, C., Wang, S., Wang, H., and Gao, P. (2014). Investigation of flow pulsation characteristic in single-phase forced circulation under rolling motion. Ann. Nucl. Energy. 64, 50-56. doi:10.1016/j.anucene.2013.09.029

Wang, G. F., Yan, C. Q., and Cao, X. X. (2011). Flow pattern characteristics of two phase flow through narrow rectangular channel under rolling condition. Atomic Energy Sci. Technol. 45 (11), 1329-1333. [in Chinese]

Xie, T. Z., Chen, B. D., and Yan, X. (2014a). Experimental research on bubble departure diameter in narrow rectangular channel under rolling motion. Atomic Energy Sci. Technol. 48 (4), 637-641. [in Chinese]

Xie, T. Z., Chen, B. D., and Yan, X. (2014b). Model development and analysis on bubble departure diameter in narrow rectangular channel under rolling motion. Atomic Energy Sci. Technol. 48 (5), 801-805. [in Chinese]

Xing, D., Yan, C., Sun, L., and Wang, C. (2013). Effect of rolling motion on singlephase laminar flow resistance of forced circulation with different pump head. Ann. Nucl. Energy.. 54, 141-148. doi:10.1016/j.anucene.2012.10.025

Yan, B. H. (2017). Review of the nuclear reactor thermal hydraulic research in ocean motions. Nucl. Eng. Des. 313, 370-385. doi:10.1016/j.nucengdes.2016.12. 041

Yan, C. Q., Yu, K. Q., and Luan, F. (2008). Rolling effects on two-phase flow pattern and void fraction. Nucl. Power Eng. 29 (4), 35-38, 49. [in Chinese]

Yan, C. X. Investigations on effects of rolling motion on characteristics of flow resistance in rod bundle (In Chinese). Harbin: Harbin Engineering Univerisity, (2015). [in Chinese]

Yang, F., Zhang, D., and Tan, C. L. (2015). Effect of marine condition on feature of natural circulation after accident in floating nuclear power plant. Nucl. Power Eng. 36 (3), 148-151. [in Chinese]

Yang, X. T., Zhu, H. Y., and Gong, H. J. (2013). Natural circulation characteristics in a symmetrical two-circuit loop under inclined condition. Nucl. Power Eng. 34 (5), 124-127. [in Chinese]

Yu, Z., Tan, S., Yuan, H., Chen, C., and Chen, X. (2016). Experimental investigation on flow instability of forced circulation in a mini-rectangular channel under rolling motion. Int. J. Heat Mass Tran. 92, 732-743. doi:10.1016/j. ijheatmasstransfer.2015.09.048

Zhang, J. H. Study on flow pattern and resistance characteristics of air-water two-phase flow in rolling motion. Harbin: Harbin Engineering Univerisity, (2009). [in Chinese]

Zhang, W. C., Tan, S. C., and Gao, P. Z. (2012). Study on chaotic characteristics of natural circulation flow instability under rolling motion. Atomic Energy Sci. Technol. 46 (6), 705-709. [in Chinese]

Zhang, W., Tan, S., Gao, P., Wang, Z., Zhang, L., and Zhang, H. (2014). Non-linear time series analysis on flow instability of natural circulation under rolling motion condition. Ann. Nucl. Energy. 65, 1-9. doi:10.1016/j.anucene.2013.10.020

Zhang, Y., Buongiorno, J., and Golay, M. Effect of platform motion on the safety performance of an offshore floating nuclear power plant. 17th International Topical Meeting on Nuclear Reactor Thermal Hydraulics. Xi' an, China, (2017). [in Chinese]

Conflict of Interest: Author XJ was employed by the company Shandong Nuclear Power Co., Ltd.

Copyright () 2020 Jie. This is an open-access article distributed under the terms of the Creative Commons Attribution License (CC BY). The use, distribution or reproduction in other forums is permitted, provided the original author(s) and the copyright owner(s) are credited and that the original publication in this journal is cited, in accordance with accepted academic practice. No use, distribution or reproduction is permitted which does not comply with these terms. 